\title{
Comparison between 2-week wait referrals prior to and during the COVID-19 pandemic
}

\author{
Authors: Katie Davies ${ }^{A}$ and Nicole Wild ${ }^{B}$
}

\section{Introduction}

With a view to contain the rapid spread of COVID-19, minimise the peak which burdens healthcare settings and flatten the curve while awaiting the development of a vaccine, individual nations worldwide have taken different approaches to containment measures. ${ }^{1}$ Since the end of March 2020, the UK government has implemented a period of social distancing and quarantine for COVID-19 symptoms. ${ }^{2}$

National data from when these measures have been implemented show reduced presentations and avoidance of healthcare services. ${ }^{3}$ A concern is regarding how cancer care will be impacted. ${ }^{4}$ Early cancer diagnosis improves outcomes. ${ }^{5}$ Rates of general practice referral for possible cancer presentations via the '2-week wait' referral systems have fallen nationally during the pandemic, such that public health organisations and charities have advised the public to seek help early. 4,6

We aimed to compare suspected cancer referrals in a general practice in two separate periods, prior to and during the COVID-19 pandemic.

\section{Methods}

We retrospectively reviewed case notes of all patients who were referred as '2-week wait' referrals in April 2019 and April 2020 from an outer city general practice. Our sample population was all patients registered at the practice including those now deceased. Patient records were reviewed using EMIS web. Patient numbers, type of referral and symptom presentations, categorised into red flag (such as lumps, bleeding or changes in swallow/voice), nonspecific symptoms (such as weight loss and fatigue) and referral based on investigations. Results were analysed using percentages.

\section{Results}

There was a greater number of suspected cancer referrals in April $2019(n=58)$ compared with $2020(n=33)$. Of those referred in April 2019, 100\% were face-to-face consultations where $24 \%$ were face-to-face in 2020. The most common referrals in April 2019 were lower gastrointestinal (GI; 31\%), dermatology (21\%)

Authors: ${ }^{A}$ Manchester University NHS Foundation Trust, Manchester, UK; ${ }^{\mathrm{B}}$ Cheadle Medical Practice, Cheadle, UK and breast (16\%), compared with breast (24\%), lower GI (15\%) and dermatology (12\%) in 2020. When quantifying symptoms, $74 \%$ were red flag, 10\% non-specific and 16\% from tests in 2019 compared with $70 \%, 9 \%$ and $21 \%$, respectively, in 2020 .

\section{Discussion}

Local research emulates findings in national data of reduced consultation for suspected cancer presentations. A greater number of referrals were completed virtually during the pandemic. Patients presented with similar proportions of red flag symptoms compared with non-specific symptoms during and prior to the COVID-19 pandemic.

Hypotheses of reasons for reduced referrals include patients' increased fear around social contact and that they feel they are wasting clinicians time. ${ }^{7}$ Research shows risk and benefit with increased virtual consultation. While minimising risk of virus transmission, virtual consultation could disproportionality negatively affect patients in more vulnerable groups. ${ }^{4}$

Research shows patients are less able to attribute vague symptoms to cancer diagnosis. ${ }^{8}$ Our results show a similar percentage of nonspecific symptoms suggesting a reduction in number as opposed to type of presentation.

Two-week wait referrals make up just under half of cancer diagnoses and $11 \%$ of referrals are found to be cancer. ${ }^{9,10}$ In order to increase patient presentation, we are using the practice website and local radio station. We will reassess in 12 months.

\section{Conflicts of interest}

None declared.

\section{References}

1 Bedford J, Enria D, Giesecke J et al. COVID-19: towards controlling of a pandemic. Lancet 2020;395:1015-8.

2 Mahase E. Covid-19: UK starts social distancing after new model points to 260000 potential deaths. BMJ 2020;368:m1089.

3 Thornton J. Covid-19: A\&E visits in England fall by $25 \%$ in week after lockdown. BMJ 2020;369:m1401.

4 Jones D, Neal RD, Duffy SR et al. Impact of the COVID-19 pandemic on the symptomatic diagnosis of cancer: the view from primary care. Lancet Oncol 2020;21:748-50.

5 Richards MA. The national awareness and early diagnosis initiative in England: assembling the evidence. Br J Cancer 2009;101(Suppl 2): S1-S4. 
6 Hiom S. How coronavirus is impacting cancer services in the UK. Cancer Research UK, 2020. https://scienceblog.cancerresearchuk. org/2020/04/21/how-coronavirus-is-impacting-cancer-services-inthe-uk [Accessed 15 July 2020].

7 Llanwarne N, Newbould J, Burt J, Campbell JL, Roland M. Wasting the doctor's time? A video-elicitation interview study with patients in primary care. Soc Sci Med 2017;176:113-22.

8 Whitaker KL, Scott SE, Winstanley K, Macleod U, Wardle J.

Attributions of cancer 'alarm'symptoms in a community sample. PLoS One 2014;9:e114028.
9 Meechan D, Gildea C, Hollingworth L et al. Variation in use of the 2-week referral pathway for suspected cancer: a cross-sectional analysis. Br J Gen Pract 2012;62:e590-7.

10 Public Health England. National cancer registration and analysis service (NCRAS). PHE, 2020. www.gov.uk/guidance/nationalcancer-registration-and-analysis-service-ncras [Accessed 15 July2020]. 